\title{
Proptosis as a presenting sign of extradural haematoma
}

\author{
C R Stewart, J F Salmon, Z Domingo, A D N Murray
}

\begin{abstract}
A conscious 15-year-old boy presented with progressive proptosis and a severe headache 2 weeks after minor blunt trauma to the head. No neurological deficit was present. Computed tomography demonstrated intracranial and intraorbital cyst-like masses. At craniotomy a subacute extradural haematoma was found which communicated with an orbital subperiosteal haematoma through a shelved orbital roof fracture. The haematomas were drained and the patient made an uneventful postoperative recovery. Although rare, an extradural haemorrhage should be considered in any patient presenting to an ophthalmologist with progressive proptosis and headache following a head injury.

(Br F Ophthalmol 1993; 77: 179-180)
\end{abstract}

Proptosis is a rare manifestation of extradural haemorrhage. To our knowledge, this association has been reported previously in only 10 cases and no reports have appeared in the ophthalmic literature. ${ }^{1-4}$ We report a unique case where proptosis and headache were the only presenting features of an extradural haematoma in a conscious 15-year-old boy.

\section{Case report}

A 15-year-old boy from a rural South African village presented to the ophthalmology department at Groote Schuur Hospital complaining of left-sided proptosis and a persistent throbbing frontal headache. Two weeks previously he had bumped his head during a game of football. He did not lose consciousness at any time. The proptosis had been noticed immediately after the trauma and had gradually increased. He had no associated nausea, vomiting, or other neurological symptoms.

On examination the patient was fully conscious with a normal affect and a Glasgow coma scale of $15 / 15$. He had no neck stiffness, cranial nerve palsy, or any other localising signs. His neurological status remained unchanged throughout his hospital stay.

The visual acuity in the right eye was $6 / 6$ and in the left $6 / 9$. On the left, $8 \mathrm{~mm}$ of non-axial

* The Glasgow coma scale is a standardised method of scoring the level of consciousness for the purpose of clinical comparison and estimation of prognosis. The higher the score the higher the level of consciousness and the better the prognosis.

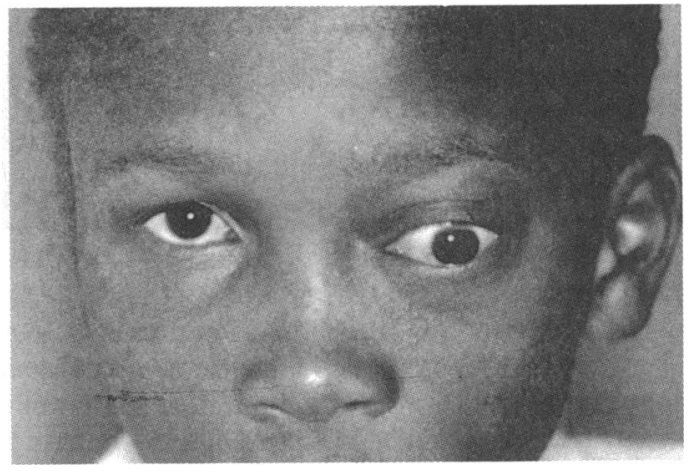

Figure 1 Preoperative appearance of the patient showing infratemporal displacement of the left eye.

proptosis was present (Fig 1). There was no bruit, the proptosis was not posture dependent, and no change was found with the valsalva manoeuvre. There was marked limitation of elevation and slight limitation of depression, abduction, and adduction. Fundal examination of the left eye revealed a hyperaemic disc, absence of spontaneous venous pulsation, and slightly dilated and tortuous retinal veins. There were horizontal choroidal folds in the left macula. The right eye was normal.

Ultrasound of the left orbit revealed a retrobulbar soft tissue mass. Skull $x$ ray and orbital $x$ ray showed no bony abnormality. Computed tomography (CT) demonstrated a large left-sided frontal intracranial cyst-like mass (Fig 2). There was midline shift with distortion of the falx cerebri and compression of the ventricular system. In addition a cyst-like mass of similar density was noted in the posterior superior aspect of the orbit, displacing the globe forward and inferiorly (Fig 2). No orbital roof fracture was demonstrated. Full blood count, erythrocyte sedimentation rate, chest $x$ ray, and ultrasound examination of the liver were normal. The Echinococcus granulosa indirect haemagglutination test was negative.

The patient subsequently underwent a left frontal craniotomy so that an excision biopsy of the intracranial 'cyst' could be performed. On elevating the frontal bone a large subacute extradural haematoma was found and drained. The haematoma was evacuated and a shelved linear fracture of the left orbital roof was discovered. On entering the orbit an encapsulated subperiosteal haematoma in the superior medial aspect of the orbit was found to be displacing the globe 
Figure 2 Coronal CT scan showing intracranial and intraorbital cyst-like masses as indicated by the arrows.

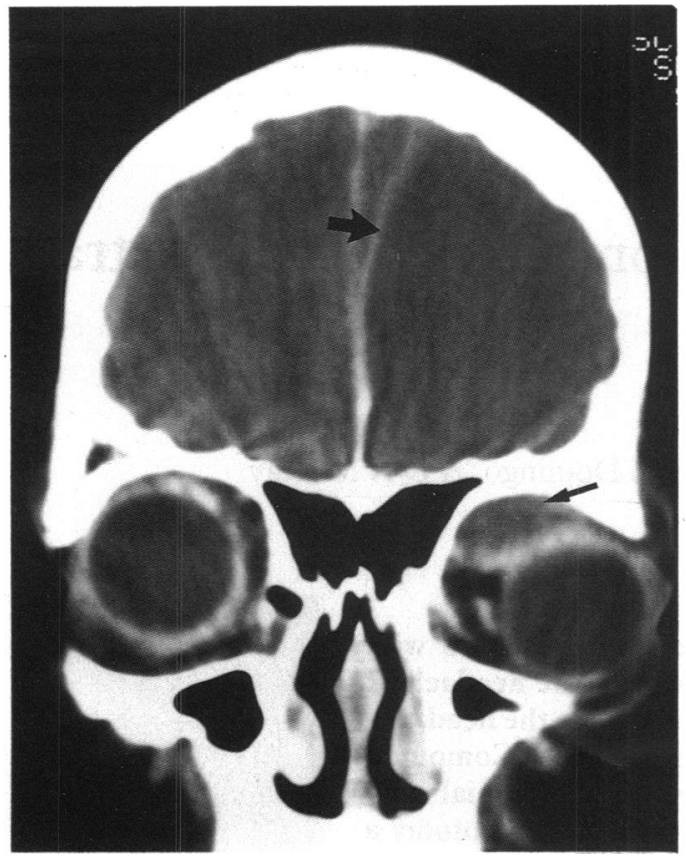

infralaterally and forward. The subperiosteal haematoma was evacuated. Postoperatively the patient made an uneventful recovery with no neurological deficit. The proptosis slowly diminished and at the last postoperative visit (3 months after surgery) had returned to normal with no residual limitation of eye movements.

\section{Comment}

The differential diagnosis of cystic lesions of the orbit and cranial cavity includes hydatid cyst (relatively common in a rural South African setting), sinus mucocele, dermoid cyst, aneurysmal bone cyst, cholesteatoma, orbital teratoma, encephalocele, and haematic cyst. ${ }^{5-7}$ While patients with haematic cysts of the orbit usually present with a subperiosteal mass months to years after blunt trauma, there has been a report of a haematic cyst presenting within 2 weeks post trauma ${ }^{8}{ }^{9}$ Haematic cysts have been associated with spontaneous haemorrhage, blood dyscrasias, vascular disease, lymphangiomas, and cavernous haemangiomas.' Although haematic cysts may erode through the bony orbit, an association with an extradural haematoma has not been described..$^{6-9}$ In this case, the finding of an extradural and orbital haematoma at the time of surgery was unexpected, particularly as the boy was conscious without neurological deficit. A similar neuroradiological clinical picture associated with an extradural haematoma has been previously reported, although in that case progressive depression of consciousness occurred. ${ }^{4}$
An extradural haematoma is a life-threatening condition with a mortality rate in children of up to $50 \% .{ }^{10}$ Computed tomography has resulted in earlier diagnosis of extradural haematoma and consequently a better prognosis. ${ }^{11}$ The clinical features of an extradural haematoma are variable, but the findings of a normal neurological examination and normal mental status in the presence of an extradural haematoma is extremely rare." Clinical features warranting the diagnosis of an extradural haematoma after head injury may develop in a period ranging from less than 1 hour to 14 days. ${ }^{12}$ Our case was therefore atypical in presentation.

In the $\mathbf{1 0}$ previously reported cases of extradural haematoma associated with proptosis, a subfrontal or frontal haematoma was found in eight cases. ${ }^{1}$ A retrobulbar haemorrhage was reported in only two cases, both of whom had an orbital roof fracture and associated frontal or subfrontal haematoma.' In those patients without a retrobulbar haemorrhage, it has been postulated that venous stasis, subarachnoid transmission of increased intracranial pressure, and ocular motor weakness may have played a role in the pathogenesis of the proptosis.

In our patient, proptosis was caused by a subperiosteal haemorrhage extending from a clinically unsuspected extradural haematoma through an orbital roof fracture. This case illustrates that an extradural haemorrhage may be the cause of a post-traumatic headache, even in the absence of neurological signs. ${ }^{12}$ Although rare, this diagnosis should be considered in any patient with cyst-like intraorbital and intracranial lesions on CT scan, particularly where a history of head injury and progressive proptosis is obtained.

1 Umansky F, Pomenanz SH. Epidural haematoma and unilateral exophthalmos - a review. Acta Neurochir (Wien) 1989; 99: 145-7.

2 Gruszkiewicz J. Ipsilateral exophthalmos in subfrontal epidural hematomas - report of four cases. $\mathcal{f}$ Neurosurg $1972 ; 37: 613-5$.

3 Watts C. Exophthalmos and epidural hematoma. South Med $\mathfrak{F}$ 1976; 69: 1539-53.

4 Bollinger B, Lomholdt Knudsen L. Frontal epidural haematoma with ipsilateral exophthalmos. Neuroradiology 1987 29: 315

5 Taylor D, ed. Paediatric ophthalmology. Oxford: Blackwell, 1990: 685 .

6 Goldberg HS, Sassani JW, Parnes RE. Traumatic intraconal hematic cyst of the orbit. Arch Ophthalmol 1992;110: 37880.

7 Shapiro A, Tso MOM, Putterman AM, Goldberg MF. A clinicopathologic study of hematic cysts of the orbit. $A m \mathcal{F}$ Ophthalmol 1986; 102: 237-41.

8 Milne HL, Leone CR, Kincaid MC, Brennan MW. Chronic haematic cysts of the orbit. Ophthalmology 1987; 94: 27I-7.

9 Mund ML. Subperiosteal hematic cyst of the orbit. Ophthalmology 1981; 88: 992-6.

10 Paşaoğlu A, Orhon C, Koç K, Selçuklu A, Akdemir H, Uzunoğlu $\mathrm{H}$. Traumatic extradural haematomas in pediatric age group. Acta Neurochir (Wien) 1990; 106: 136-9.

11 Snyder HS, Salo D. Epidural hematoma: an unusual presentation. Am f Emerg Med 1990; 8: 538-41.

12 Jamieson KG, Yelland JDN. Extradural haematoma - report of 167 cases. 7 Neurosurg $1968 ; 29$ : 13-23. 